\title{
Kozlu Deresinde (Zonguldak) Su Kalitesinin İncelenmesi
}

\section{Özgür Zeydan ${ }^{1} \oplus$, Nizamettin Özdoğan ${ }^{1, *} \oplus$, Şeyma Pınar Taştepe ${ }^{1} \odot$, Dilek Demirtaş ${ }^{1} \Subset$}

${ }^{1}$ Zonguldak Bülent Ecevit Üniversitesi, Mühendislik Fakültesi, Çevre Mühendisliği Bölümü, 67100, Zonguldak.

\section{Özet}

Günümüzde su kullanımı nüfusa bağlı olarak her geçen gün artmaktadır. Su ihtivacının artması, su kaynaklarının kontrolsüzce kullanımına sebep olmaktadır. Genellikle az gelişmiş ve gelişmekte olan ülkelerde atık sular, arıtılmadan doğrudan alıcı ortamlara deșarj edilmektedir. Bu durum su kaynaklarının kalitesini düş̈̈rmekte ve akarsulardan sağlanacak faydayı kısıtlamaktadır. Bu çalışma, Zonguldak Kozlu Deresinde yapılan ilk kapsamlı su kalitesi çalışmasıdır. Derenin su kalitesini belirleyebilmek için 2017 Haziran ve Aralık aylarında olmak üzere 2 farklı zamanda belirlenen 6 farklı noktadan numuneler alınmıştır. Alınan numunelerde Kimyasal Oksijen İhtiyacı, Biyokimyasal Oksijen İhtiyacı, Askıda Katı Madde, pH, Toplam Kjeldahl Azotu, fosfor, iletkenlik ile yağ ve gres tayini yapılmıştır. Kimyasal Oksijen İhtiyacı ve Askıda Katı Madde değerleri için Coğrafi Bilgi Sistemi yazılımı kullanılarak su kirliliğini gösteren tematik haritalar hazırlanmıştır. Yapılan analizler sonucunda, Kozlu Deresi'ndeki su kalitesinin Yerüstü Su Kalitesi Yönetmeliği'ne göre 4. Sinıf olduğu görülmüştür.

Anahtar Sözcükler

Fiziko-Kimyasal Parametreler, Coğrafi Bilgi Sistemleri, Kozlu Deresi, Su Kalitesi

\section{Investigation of Water Quality in Kozlu Creek (Zonguldak)}

\begin{abstract}
Today, the consumption of water is increasing day by day due to population. This increase of demand for water leads to an uncontrolled use of water supplies. Generally, in underdeveloped and developing countries, wastewater is discharged directly to receiving environments without treatment. This situation causes a decrease in the quality of these water supplies and restricts the benefits of streams. In this paper, we present the first extensive study on the quality of water of Kozlu Creek in Zonguldak. To determine the quality of the stream's water, we have collected water samples from 6 different locations on the creek, on two separate dates in June and December of 2017. These samples have been tested to determine their levels of Chemical Oxygen Demand, Biological Oxygen Demand, Total Suspended Solids, pH, Total Kjeldahl Nitrogen, phosphorus, conductivity, oil and grease content. We used Geographical Information Systems to create thematic maps that demonstrate the level of pollution of water in terms of Chemical Oxygen Demand and Total Suspended Solids parameters. As a result of the analyzes, it was found that the water quality in Kozlu Creek was in the 4th class according to the Regulation on Surface Water Quality.
\end{abstract}

\section{$\underline{\text { Keywords }}$}

Physico-Chemical Parameters, Geographical Information Systems, Kozlu Creek, Water Quality

\section{Giriş}

Dere, çay ve nehir gibi akarsular başlıca tatlı su kaynaklarıdır. Bu kaynaklardan elde edilen sular içme suyu, evlerde ve sanayide kullanma suyu ve tarımda sulama suyu olarak kullanılır. Ayrıca, akarsular enerji üretiminde de önemli bir yere sahiptir (Hacioglu ve Dulger 2009). Diğer yandan, akarsular çevre kirliliğinden en çok etkilenen ekosistemlerdir. Avrupa Çevre Ajansı tarafından önerilen DPSIR (Driver, Pressure, State, Impact, Response - İtici güç, Bask1, Durum, Etki, Tepki) çerçevesi su kalitesine uygulandığında ekonomik gelişmeler itici güç, atık deşarjları baskı, akarsu ortamındaki su kalitesi durum, su kalitesinin bozulmasıyla ortaya çıkan halk sağlı̆̆1 ve çevre sağlığı sorunları etki ve bozulmayı önlemek için alınan tedbirler ise tepki olarak karşımıza çıkmaktadır (Tsuzuki 2015). Son yıllarda dünya çapında kullanılan su miktarı ciddi oranda artış göstermektedir (Udimal vd. 2017). Artan nüfus, kentleşme, sanayileşme, iklim değişikliği, aşırı sulama ve tarımda bilinçsiz gübre kullanımı gibi faktörler su kaynakları üzerinde baskı oluşturmaya başlamıştır (Maraşlığlu vd. 2017). Yeterli arıtma yapılmamış evsel ve endüstriyel atık su deşarjları ile tarım alanlarından kaynaklı kirleticiler nedeniyle sucul ekosistemler kendini temizleyebilme kapasitesini kaybetmekte ve su kalitesi bozulmakta, suyun kullanım alanları olumsuz etkilenmekte ve su ortamında yaşayan canlılar da yok olma tehlikesi ile karşı karşıya kalmaktadırlar (Toroğlu vd. 2006; Hacioglu ve Dulger 2009; Mutlu ve Uncumusaoğlu 2016).

\footnotetext{
* Sorumlu Yazar: Tel: +90 (372) 2912572 Faks: +90 (372) 2574023
}

E-posta: ozgurzeydan@yahoo.com (Zeydan Ö), nozdogan@beun.edu.tr (Özdoğan N) pinartastepe@hotmail.com (Taştepe Ş.P), diilek.demirtas@gmail.com (Demirtaş D)
Gönderim Tarihi / Received : 07/08/2018

Kabul Tarihi / Accepted : :21/11/2018 
Ayrıca, kullanılabilir su kaynaklarının azalması nedeniyle su stresi oluşmakta ve kirli suların kullanılması için yapılması gereken arıtma gereksinimi de artmaktadır. Dolayısıyla, su kalitesinin izlenmesi günümüzde çevre yönetimi açısından öncelikli bir konu haline gelmiştir (Boyacioglu 2006; Koç 2010).

Su kalitesinin belirlenmesindeki başlıca amaç kirliliğe sebep olan kaynakların belirlenmesi ve bu kaynakların kontrolü ile suyun uygun kalitede kullanıma sunulmasıdır (Boyacioglu 2006). Son yıllarda hem ülkemizde hem de diğer ülkelerde su kalitesinin belirlenmesi ile ilgili çok sayıda çalışma yapılmıştır. Boyacioglu (2006) Büyük Menderes Nehri'nde 21 ayrı istasyondan almış olduğu örneklerde toplam katı madde (TKM), nitrat-azotu $\left(\mathrm{NO}_{3}-\mathrm{N}\right)$, Toplam Kjeldahl azotu (TKN), biyokimyasal oksijen ihtiyacı $\left(\mathrm{BOI}_{5}\right)$ ve kimyasal oksijen ihtiyacı (KOİ) gibi parametreleri incelemiş; kurak ve yağışlı dönem için su kalitesini etkileyen etmenleri faktör analizi ile belirlemiştir. Biga (Kocabaş) Çayı'nda yapılan bir çalışmada ise 10 tane ağır metal $(\mathrm{Pb}, \mathrm{Cu}, \mathrm{Cd}, \mathrm{Cr}, \mathrm{Zn}, \mathrm{Al}, \mathrm{Fe}, \mathrm{Ni}, \mathrm{Co}, \mathrm{Mn})$ ile 7 tane fiziko-kimyasal su kalitesi parametresi (sıcaklık, tuzluluk, iletkenlik, TKM, pH, indirgenme yükseltgenme potansiyeli ve ÇO) ölçülmüştür. Ağır metaller içinde özellikle krom konsantrasyonunun yüksek olduğu belirlenmiştir. Kirletici kaynaklar olarak da tabakhaneler ile birlikte seramik fabrikası ve Çan Termik Santrali belirtilmiştir (Yayıntas vd. 2007). Biga (Kocabaş) Çayı'nda yapılan bir başka çalışmada da fiziko-kimyasal parametreler ise birlikte biyolojik parametreler de aylık olarak izlenmiş ve sonuçlar SKKY'ne göre yorumlanmıştır. Çalışmada, 3 örneklem noktasında da su kalitesinin BOİ ${ }_{5}$ ve fekal koliform açısında 4. sınıf, toplam koliform açısından da 3. sınıf olduğu bulunmuş ve suyun ciddi oranda enfeksiyon riski taşıdığı bildirilmiştir (Hacioglu ve Dulger 2009). Mert Çayı'nda (Samsun) yapılan bir çalışmada da 6 istasyonda aylık olarak toplam 9 tane su kalitesi parametresi izlenmiş; kentleşme ve endüstrinin yoğun olduğu bölümde Mert Çayı'nın kısmi kirlilik tehdidi altında olduğu vurgulanmıştır (Maraşlığlu vd. 2017).

Coğrafi Bilgi Sistemleri (CBS) coğrafi koordinatlara sahip olan verinin toplanması, bilgisayar ortamında işlenmesi, analiz edilmesi ve istenilen amaçlar doğrultusunda sunulması için kullanılan bir sistem bütünüdür. CBS, su kaynaklarının yönetimi, taşkın analizi, su kalitesinin belirlenmesi ve izlenmesi gibi alanlarda kullanılmaktadır. Güney Kore'deki Han nehir havzasında 8 su kalitesi parametresinin (sıcaklık, pH, ÇO, BOİ, KOİ, çözülmüş katılar, toplam fosfor ve toplam azot) mekânsal analizi CBS yardımıyla yapılmıştır. Çalışma sonucunda kentsel bölgelerin, su kirliliği ile ilişkili olduğu ve pH hariç diğer su kalitesi parametrelerindeki değişimleri açıklamak için kullanılabileceği belirtilmiştir (Chang 2008). A.B.D.'nin Winconsin Eyaletinde yapılan başka bir çalışmada arazi kullanımı ile su kalitesi arasındaki ilişkinin belirlenmesinde havza bazında CBS tabanlı bir yaklaşım geliştirilmiştir. Çalışma sonucunda incelenen 21 su kalitesi parametresinden 14 tanesinin kentsel ve tarım alanları ile pozitif, orman ve bataklık alanlar ile de negatif korelasyon gösterdiği bulunmuştur (Liu vd. 2009). Çin Halk Cumhuriyeti'ndeki Honghe Nehir Havzası'nda yapılan bir çalışmada da 67 örnekleme noktasında 6 farklı su kalitesi parametresi (ÇO, amonyak azotu $\left(\mathrm{NH}_{3}-\mathrm{N}\right)$, nitrat azotu $\left(\mathrm{NO}_{3}-\mathrm{N}\right)$, nitrit azotu $\left(\mathrm{NO}_{2}-\mathrm{N}\right)$, toplam azot ve toplam fosfor) analizleri yapılmıştır. Elde edilen sonuçlar CBS ortamında görselleştirilerek potansiyel kirli bölgeler belirlenmiştir (Yan vd. 2015). Büyük Menderes nehrinde yapılan bir başka çalışmada ise 12 örneklem noktasında, sulama ve kış dönemleri için çeşitli su kalitesi parametrelerine bakılmış elde edilen bulgular ile nehrin su kalitesi haritası CBS ortamında hazırlanmıştır. Bu çalışmada su kalitesinin, Su Kirliliği Kontrolü Yönetmeliği’ne (SKKY) göre 3. sınıf olduğu belirtilmiş; kirlilik kaynağının da tarımsal aktiviteler, yerleşim yerlerinin atık suları ve jeotermal enerji üretim tesislerinin atık suları olduğu belirlenmiştir (Koç 2010). CBS'nin akarsularda su kalitesinin belirlenmesi amacıyla kullanıldığı bir başka çalışma ise Aksu Nehri’nde yapılmıştır. 21 su kalitesi izleme istasyonunda toplam 24 farklı su kalitesi parametresi mevsimsel olarak ölçülmüştür. 3 istasyonda çözünmüş oksijen (ÇO) ve bulanıklık değerlerinin mevzuatta verilen sınır değeri aştığı, ayrıca tüm istasyonlarda KOİ değerinin Dünya Sağlık Örgütü (WHO) tarafindan belirlenen sınır değeri aştığı bildirilmiştir (Şener vd. 2017).

Çalışma alanı olan Kozlu Deresi’nde (İhsaniye Deresi) su kalitesi, dereye evsel ve endüstriyel atık suların hiçbir arıtımdan geçmeden deşarj edilmesi sonucunda bozulmuştur. Dere ile ilgili literatürde çok az sayıda çalışma bulunmaktadır. Ekinci (2003) tarafından yapılan taşkın analizi sırasında, derenin ortalama debisinin $0.485 \mathrm{~m}^{3} / \mathrm{s}$ ve ortalama hızın ise $0.443 \mathrm{~m} / \mathrm{s}$ olduğu belirtilmiştir. Altaş ve Büyükgüngör (2007) Kozlu Deresi'nden Karadeniz'e taşınan ağır metal miktarının oldukça az (0.053 ton $\mathrm{Cd}^{2+} / \mathrm{y} 1$ l) olduğunu belirtmiştir. Tuncer vd. (1998) tarafından yapılan çalışmada ise Kozlu Deresi'nde kirlenmenin başlangıç safhasında olduğu su kalitesinin izlenmesi gerektiği vurgulanmıştır. Kozlu Deresi için önemli kirletici parametrelerin KOİ, BOİ ${ }_{5}, \mathrm{NO}_{2}, \mathrm{NH}_{3}$ ve toplam fosfor olduğu ifade edilmiştir. Derenin Karadeniz'e taşıdığ 1 kirlilik yüklerinin ise 1200 ton/y1l KOİ, 1200 ton/yıl BOİ, 1 ton/yıl NO $2-\mathrm{N}_{2}, 11$ ton/y1l $\mathrm{NO}_{3}-\mathrm{N}, 48$ ton/y1l $\mathrm{NH}_{3}-\mathrm{N}, 2.4$ ton/y1l toplam $\mathrm{P}, 1700$ ton/y1l toplam kat1 madde ile $1 \mathrm{~kg} / \mathrm{y}_{1} \mathrm{Cd}^{2+} \mathrm{olduğu}$ bildirilmiştir (Tuncer vd. 1998). Hem Altaş ve Büyükgüngör (2007), hem de Tuncer vd. (1998) tarafından yapılan çalışmalarda derenin debisinin $0.02 \mathrm{~km}^{3} / \mathrm{y}$ ll olduğu görülmektedir. Özkan vd. (2017) ise bu iki çalışmadaki verilerin birbiri ile uyuşmadığını vurgulamıştır. Literatürde, Kozlu Deresi’ne ait su kalitesi alanında yapılmış çalışmalarda sadece derenin Karadeniz'e taşıdığı kirlilik yükleri belirtilmiştir.

Bu çalışma, Kozlu Deresi’nde su kalitesinin belirlenmesi amacıyla yapılan ilk çalışma olma niteliği taşımaktadır. Bu nedenle derede, su kalitesi analizleri yapılmış, Yerüstü Su Kalitesi Yönetmeliği'ne göre yorumlanmış, elde edilen değerler üzerinden derenin kirlilik durumu Coğrafi Bilgi Sistemleri ortamına aktarılmış ve yorumlanmıştır. 


\section{Materyal ve Yöntem}

\section{1. Çalışma Alanı}

Çalışma alanı, Zonguldak ili Kozlu ilçesinde yer alan Kozlu Deresi'dir. Zonguldak'ın içme suyunu sağlayan Ulutan Barajı'nın çıkışından başlayan Kozlu deresi Karadeniz'in en derin kıyılarının bulunduğu bir bölgede denize dökülmektedir. Kozlu deresi üzerinde bulunan "Kozlu Sanayi Sitesi” ve "Türkiye Taşkömürü Kurumu (TTK) Kozlu Ocak İşletmesi" atıklarını herhangi bir arıtma olmadan, doğrudan dereye deşarj etmektedir (Altin vd. 2009). Ayrıca, konut alanlarından kaynaklı atık sular da bu dereye dökülmektedir. Dere, hem ocak içi atık sularını hem de Kozlu yerleşim birimlerinden gelen kanalizasyon atıklarını denize taşıyan üstü açık kolektör konumundadır.

Zonguldak ili iklimi ılıman Karadeniz iklimidir. Bütün mevsimler ılık ve yağışlı geçer ve bölgede kurak mevsim görülmez. Yağışlar sıklıkla sonbahar ve kış mevsimlerinde olmaktadır. Mevsimler ve gece gündüz arasında sıcaklık farkı azdır. İklim deniz kısımlarında daha yumuşak iç kesimlerde ise deniz taraflarına kıyasla serttir (URL-1 2016). 78 yıllık rasat verisi sonuçlarına göre, çalışma alanında ortalama sıcaklık $13.6^{\circ} \mathrm{C}$ 'dir. Ocak ve şubat en soğuk aylar; temmuz ve ağustos ise en sıcak aylardır. Yılın yaklaşık 146 günü yağı̧̧ı geçmektedir. Metrekareye düşen yıllık toplam yağış miktarı 1219 mm'dir. Nisan, Mayıs, Haziran ve Temmuz ayları en kurak aylardır. Kasım, Aralık ve Ocak ayları ise en yağışlı aylar olarak görülmektedir (URL-1 2016; MGM 2018).

Bu çalışmada, $7.3 \mathrm{~km}$ uzunluğundaki Kozlu Deresi boyunca 6 farklı noktadan su numunesi alınmıştır. Su numunesi alınan noktaların UTM koordinatları (36. dilim) Tablo 1'de verilmiş ayrıca, Kozlu deresi üzerinde numune alınan noktalar ile başlıca kirletici kaynakları harita üzerinde gösterilmiştir (Şekil 1). Derenin sağ tarafindaki koldan su kalitesi örneğinin alınmamasının sebebi bu bölgede önemli bir kirletici kaynağı bulunmamasıdır.

Tablo 1: Su numunesi alınan noktaların koordinatları

\begin{tabular}{|c|c|c|}
\hline \multirow{2}{*}{ Nokta No. } & \multicolumn{2}{|c|}{ Koordinat (m) } \\
\cline { 2 - 3 } & $\mathbf{X}$ & Y \\
\hline 1 & 397424 & 4586459 \\
\hline 2 & 397752 & 4587163 \\
\hline 3 & 396801 & 4587687 \\
\hline 4 & 396014 & 4587509 \\
\hline 5 & 395440 & 4587782 \\
\hline 6 & 395039 & 4587965 \\
\hline
\end{tabular}

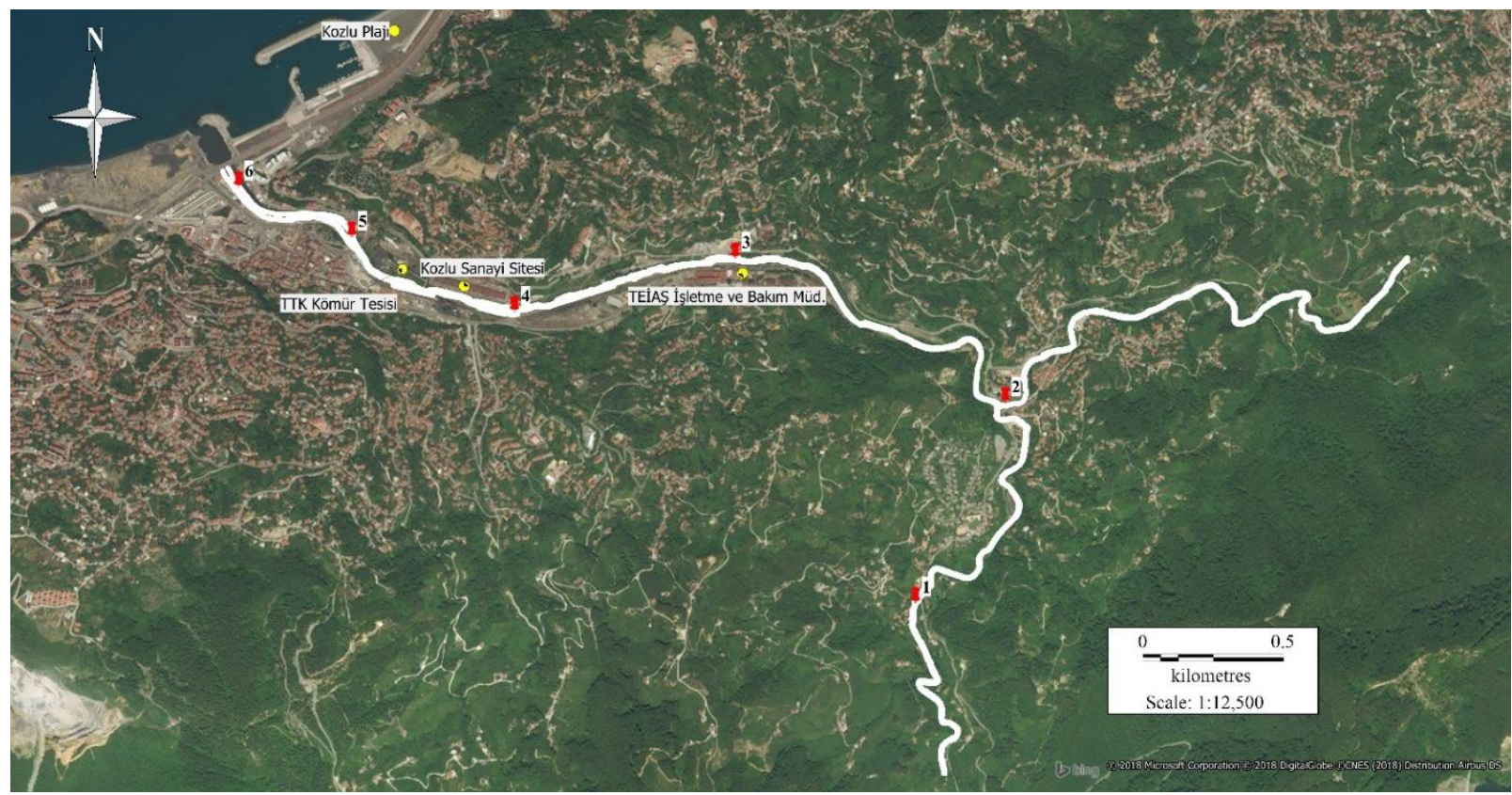

Şekil 1: Çalışma alanının haritası 


\subsection{Su Kalitesi Analizleri}

Kozlu deresinin su kalitesi parametrelerini belirlemek için su örnekleri kurak ve yağışlı mevsim olan iki ayrı dönemde (2017 Haziran ve Aralık) alınmış ve aynı gün çevre mühendisliği laboratuvara getirilerek laboratuvar ortamında analizleri gerçekleştirilmiştir. pH ve elektriksel iletkenlik $(\mu \mathrm{S} / \mathrm{cm})$ değerleri standart solüsyonlar kullanılarak Thermo Scientific Orion 5 Star cihazı ile ölçülmüştür. Kimyasal oksijen ihtiyacı (KOİ), kapalı reflux yöntemi kullanılarak su numunesindeki organik maddenin yüksek sıcaklıkta konsantre sülfirik asit içinde potasyum dikromat ile gümüş katalizör yardımıyla karbondioksit $\left(\mathrm{CO}_{2}\right)$ ve suya $\left(\mathrm{H}_{2} \mathrm{O}\right)$ oksitlenmesi yöntemiyle Thermo Scientific Helios Aquamate UV/Vis spektrofotometre cihazı ile ölçülmüştür. Biyokimyasal oksijen ihtiyacı (BOİ ${ }_{5}$ ), organik maddenin parçalanmasıyla açığa çıkan $\mathrm{CO}_{2}$ 'nin kısmı basıncının ölçülmesi esasına dayanır ve oksitop (WTW Weilheim, Almanya) cihazıyla ölçülmüştür. Askıda katı madde (AKM) miktarı, sabit tartım yöntemiyle, Toplam Kjeldahl azotu (TKN), distilasyon-amonyak tayin yöntemi kullanılarak Büchi Digest System K-437 cihazı ile tespit edilmiştir. Fosfor tayini kolorimetrik yöntemlerden biri olan kalay klorür metoduyla, yağ-gres analizleri ise su numunelerinin içinde bulunan yağ ve gresin çözücü olarak kullanıldığı hekzanla birlikte ektraksiyona tabi tutularak kullanılan soxhlet aparatının yardımıyla laboratuvar ortamında tayin edilmiştir. Örneklem noktalarından alınan su numunelerinin analizleri Standart Metotlara göre yapılmıştır (APHA 2005). Su kalite sınıflarının oluşturulmasında ve ölçülen su parametrelinin yorumlanmasında Yerüstü Su Kalitesi Yönetmeliği’nin (YSKY) ekinde (EK-5) yer alan “Kıta içi Yerüstü Su Kaynaklarının Genel Kimyasal ve Fizikokimyasal Parametreler Açısından Sınıflarına Göre Kalite Kriterleri” esas alınmış ve Tablo 2’de gösterilmiştir.

Tablo 2: Su kalitesi sınıfları (URL-2 2012)

\begin{tabular}{|c|c|c|c|c|}
\hline \multirow{2}{*}{ Su Kalite Parametreleri } & \multicolumn{4}{|c|}{ Su Kalite Sınıfları } \\
\hline & I (çok iyi) & II (iyi) & III (orta) & IV (zayıf) \\
\hline $\mathrm{pH}^{*}$ & $6-9$ & $6-9$ & $6-9$ & $6-9$ \\
\hline İletkenlik $(\mu \mathrm{S} / \mathrm{cm})$ & $<400$ & 1000 & 3000 & $>3000$ \\
\hline Yağ ve Gres $(\mathrm{mg} / \mathrm{L})$ & $<0.2$ & 0.3 & 0.5 & $>0.5$ \\
\hline Toplam fosfor (mg P/L) & $<0.08$ & 0.2 & 0.8 & $>0.8$ \\
\hline Kimyasal oksijen ihtiyacı (KOİ) (mg/L) & $<25$ & 50 & 70 & $>70$ \\
\hline Biyolojik oksijen ihtiyacı $\left(\mathrm{BOI} \dot{I}_{5}\right)(\mathrm{mg} / \mathrm{L})$ & $<4$ & 8 & 20 & $>20$ \\
\hline Toplam Kjeldahl Azotu (mg/L) & $<0.5$ & 1.5 & 5 & $>5$ \\
\hline
\end{tabular}
yapılan yönetmelikteki değişiklik sonucu yönetmeliğin adı Yerüstü Yüzeysel Su Kalitesi Yönetmeliği, pH değerleri ise 6-9 olarak değiştirilmiştir.

\section{Bulgular ve Tartışma}

Kozlu deresinden 2017 Haziran ve Aralık aylarında alınan örneklerin laboratuvar ortamında analiz edilmesi sonucunda bulunan su kalitesi parametreleri (pH, iletkenlik, KOİ, BOİ, AKM, Fosfor, TKN ve yağ-gres) Tablo 3 ve 4'de verilmiştir. Haziran döneminde altı farklı noktadan alınan örneklerde KOİ, pH, Fosfor, AKM ve İletkenlik parametrelerine bakılırken, Aralık döneminde ise altı farklı noktada $\mathrm{pH}$, İletkenlik, KOİ, BOİ 5 , Fosfor, TKN, AKM ve yağ-gres parametrelerine bakılmıştır.

Tablo 3: Haziran 2017 dönemi su kalitesi analiz sonuçları

\begin{tabular}{|c|c|c|c|c|c|}
\hline Nokta & $\begin{array}{c}\text { KOI } \\
(\mathbf{m g} / \mathbf{L})\end{array}$ & $\mathbf{p H}$ & $\begin{array}{c}\text { Fosfor } \\
(\mathbf{m g} / \mathbf{L})\end{array}$ & $\begin{array}{c}\text { AKM } \\
(\mathbf{m g} / \mathbf{L})\end{array}$ & $\begin{array}{c}\text { İletkenlik } \\
(\boldsymbol{\mu S} / \mathbf{c m})\end{array}$ \\
\hline 1 & 320 & 8.40 & $<0.05$ & 25 & 403 \\
\hline 2 & 256 & 7.89 & $<0.05$ & 35 & 303 \\
\hline 3 & 544 & 8.64 & $<0.05$ & 112 & 1206 \\
\hline 4 & 416 & 8.58 & $<0.05$ & 59 & 971 \\
\hline 5 & 480 & 8.00 & $<0.05$ & 45 & 785 \\
\hline 6 & 656 & 8.42 & 0.183 & 88 & 2823 \\
\hline
\end{tabular}


Tablo 4: Aralık 2017 dönemi su kalitesi analiz sonuçları

\begin{tabular}{|c|c|c|c|c|c|c|c|c|}
\hline Nokta & $\begin{array}{c}\text { BOİ5 } \\
(\mathbf{m g} / \mathbf{L})\end{array}$ & $\begin{array}{c}\text { KOI் } \\
(\mathbf{m g} / \mathbf{L})\end{array}$ & $\mathbf{p H}$ & $\begin{array}{c}\text { Fosfor } \\
(\mathbf{m g} / \mathbf{L})\end{array}$ & $\begin{array}{c}\mathbf{A K M} \\
(\mathbf{m g} / \mathbf{L})\end{array}$ & $\begin{array}{c}\text { TKN } \\
(\mathbf{m g} / \mathbf{L})\end{array}$ & $\begin{array}{c}\text { Yağ ve Gres } \\
(\mathbf{m g} / \mathbf{L})\end{array}$ & $\begin{array}{c}\text { İletkenlik } \\
(\boldsymbol{\mu} \mathbf{S} / \mathbf{c m})\end{array}$ \\
\hline 1 & - & 160 & 8.35 & $<0.05$ & 0.005 & - & - & 317 \\
\hline 2 & - & 192 & 7.97 & $<0.05$ & 0.011 & - & - & 287 \\
\hline 3 & - & 288 & 8.18 & $<0.05$ & 0.011 & 6.25 & 0.0005 & 315 \\
\hline 4 & - & 384 & 8.36 & $<0.05$ & 0.012 & - & - & 452 \\
\hline 5 & - & 224 & 8.35 & $<0.05$ & 0.034 & - & - & 626 \\
\hline 6 & 180 & 352 & 8.31 & 0.172 & 0.021 & 144 & 0.0014 & 502 \\
\hline
\end{tabular}

Su kalitesinin belirlenmesi için sudaki fiziksel, kimyasal ve mikrobiyolojik parametrelerin ölçülmesi gerekmektedir (Maraşlığlu vd. 2017). Bu parametrelerin ölçülmesi ile suyun kirlilik durumu ve kirletici kaynakları hakkında fikir sahibi olmak mümkündür. Ancak, buradaki en büyük zorluk ölçülmesi gereken çok sayıda parametrenin olmasıdır (Boyacioglu 2006).

Suyun asidik veya alkaline oluşunu gösteren $\mathrm{pH}$, sudaki canlı hayatı için önemlidir. Çoğu balık türü pH'ın 6.5-8.5 olduğu aralıkta yaşamlarını sürdürürler (Alam vd. 2007; Birinci 2017). Asidik pH değerlerinde metallerin çözünürlüğü de artmaktadır (Maraşlıoğlu vd. 2017). Bu nedenle, sucul yaşamın metal kirliliğinden etkilenmemesi için suyun pH değerinin biraz alkali olması tercih edilir (Hacioglu 2009). Yapılan çalışmada derede Haziran ayında en düşük pH değeri 7.89; Aralık ayında ise 7.97 olarak ölçülmüştür. Haziran ayında en yüksek pH değerleri 3. ve 4. örneklem noktalarında sırasıyla 8.64 ve 8.58 olarak ölçülmüştür. Aralık ayında ise en yüksek ölçülen pH değeri 8.36 ile 4 . numune alma noktasındadır. Kış dönemi pH değerleri 7.97 ile 8.36 arasında değişmektedir. Dolayısıyla, Kozlu Deresi'ndeki su kalitesinin $\mathrm{pH}$ açısından yağışlı dönemde kurak döneme oranla biraz daha temiz olduğu söylenebilir. Karadeniz'de yapılan su kalitesi çalışmalarında suların bir miktar bazik olduğu belirtilmiştir (Maraşlıoğlu vd. 2017). Dolayısıyla, bu çalışmada elde edilen sonuçlar literatür ile uyumluluk göstermektedir.

Fosfor, sucul ekosistemlerde ötrofikasyona sebep olan sınırlayıcı besin maddelerinden biridir. Evsel atık sulardaki deterjan artıkları, gıda endüstrisi atıkları ve tarımda kullanılan suni gübreler sudaki fosfor kaynaklarıdır (Maraşlığlu vd. 2017; Şener vd. 2017). Yapılan toplam fosfor ölçümlerinde 6. örneklem noktasında Haziran ayında 0.183 mg/L, Aralık ayında da $0.172 \mathrm{mg} / \mathrm{L}$ değerleri elde edilmiştir. Diğer noktalardaki toplam fosfor değeri $0.05 \mathrm{mg} / \mathrm{L}$ 'den küçük bulunmuştur. Fosfor değerinin kurak dönemde daha yüksek olduğu bilinmektedir (Søndegaard vd. 2001). Bunun nedeninin yağışların artması sonucu derede meydana gelen seyrelme olduğu düşünülmektedir. Sonuçlar yönetmelikle karşılaştırıldığında su kalitesinin fosfor açısından II. sınıf olduğu belirlenmiştir.

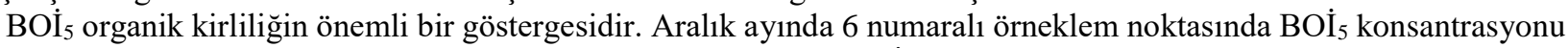
$180 \mathrm{mg} / \mathrm{L}$ olarak belirlenmiştir (Tablo 4). Bu çalışmada bulunan BOİ 5 değeri, YSKY açısından oldukça yüksektir. Bu nedenle, su kalitesinin IV. sınıf olduğu açıkça görülmektedir. Biga Çayı'nda yapılan su kalitesi çalışmasında benzer şekilde yüksek BOİ 5 değerleri rapor edilmiştir (Hacioglu ve Dulger 2009).

KOİ testi suda bulunan organik ve inorganik maddelerin bozunması için gerekli olan oksijen miktarının belirlenmesi amacıyla yapılır. Yüksek KOİ değerlerin suyun kirli olduğu kabul edilir (Mutlu ve Uncumusaoğlu 2016; Şener vd. 2017). KOİ konsantrasyonun kurak dönemdeki en yüksek ölçüm değeri 6 . noktada $656 \mathrm{mg} / \mathrm{L}$ ve en düşük ölçüm değeri de 2 . noktada 256 mg/L'dır. Aralık ayındaki ölçümlerde ise bu değerlerin en yüksek 6. noktada $352 \mathrm{mg} / \mathrm{L}$ ve en düşük 1 . noktada $160 \mathrm{mg} / \mathrm{L}$ olduğu belirlenmiştir. Dereye yapılan atık su deşarjları yükssek KOİ konsantrasyonlarını ölçülmesinin başlıca sebebidir. Kış aylarında yağışlara bağlı olarak KOİ konsantrasyonun seyrelme nedeniyle azaldığı görülmektedir. YSKY'ne göre KOİ konsantrasyonlarına bakıldığında su kalitesinin IV. sınıf olduğu belirlenmiştir. Ülkemizde yapılan su kalitesi çalışmalarında, Kozlu Deresi'ndeki KOİ değerlerine kıyasla çok daha düşük değerlerin rapor edildiği görülmektedir (Boyacioglu 2006; Mutlu ve Uncumusaoğlu 2016; Şener vd. 2017).

Suda azot nitrit $\left(\mathrm{NO}_{2}\right)$, nitrat $\left(\mathrm{NO}_{3}\right)$ ve amonyum $\left(\mathrm{NH}_{4}\right)$ azotu şeklinde bulunabilir ve bu bileşiklerin yüksek konsantrasyonları sucul yaşam için toksik etkiler gösterir (Maraşlıŏ̆lu vd. 2017). Azot, ötrofikasyonda rol oynayan sınırlayıcı elementlerden biridir (Şener vd. 2017). Ayrıca amonyum azotu nitrifikasyon sürecinde sudaki çözünmüş oksijeni de tüketmektedir (Mutlu ve Uncumusaoğlu 2016). Toplam Kjeldahl Azotu, organik azot ve amonyak azotunun toplamıdır. Tablo 4'de TKN değerleri Aralık ayında 3. noktada $6.25 \mathrm{mg} / \mathrm{L}, 6$. noktada ise $144 \mathrm{mg} / \mathrm{L}$ olarak bulunmuştur. YSKY'ne göre 3 ve 6 numaralı örneklem noktalarında su kalitesi değerleri IV. sınıf olarak tespit edilmiştir. Diğer örneklem noktaları için tespit edilmeye çalışılan TKN değerleri YSKY'e göre belirlenen alt limit değerinin altında olduğundan Tablo 4'de gösterilmemiş, dolayısıyla sınıflama yapılamamıştır. 6. numune noktasındaki TKN değerinin çok yüksek olması Kozlu Belediyesi'nin atık sularının arıtma olmaksızın bu nokta yakınından dereye deşarj edilmesi olarak açıklanabilir. Literatürdeki çalışmalarda genellikle daha düşük TKN değerleri rapor edilmiştir: Büyük Menderes Nehri'nde kurak dönem ortalaması $0.83 \mathrm{mg} / \mathrm{L}$, yağışlı dönem ortalaması $0.93 \mathrm{mg} / \mathrm{L}$ (Boyacioglu 2006), Aksu Nehri'nde kurak dönem ortalaması $0.52 \mathrm{mg} / \mathrm{L} \mathrm{NH}_{4}{ }^{-}-\mathrm{N}$ ve yağışlı dönem ortalaması $0.46 \mathrm{mg} / \mathrm{L} \mathrm{NH}_{4}{ }^{+}-\mathrm{N}$ (Şener vd. 2017) ve Mert Çayı'nda da ortalama $0.01 \mathrm{mg} / \mathrm{L} \mathrm{NH}_{4}{ }^{+}-\mathrm{N}$ (Maraşlığ lu vd. 2017). 
Tablo 4'de, Aralık ayında, Kozlu deresinde tespit edilen en yüksek yağ ve gres değeri 6 numaralı örneklem noktasında $0.0014 \mathrm{mg} / \mathrm{L}$, en düşük değer ise 3 numaralı örneklem noktasında $0.0005 \mathrm{mg} / \mathrm{L}$ olarak tespit edilmiştir. YSKY'e göre 6 numaralı örneklem noktası için yağ-gres verileri incelendiğinde 1. Sınıf, 3 numaralı örneklem noktasında ise yine 1. Sınıf olarak su kalitesi sınıflandırılmıştır. Diğer örneklem noktaları için tespit edilmeye çalışılan yağ ve gres değerleri YSKY'e göre belirlenen alt limit değerinin altında olduğundan sınıflama yapılamamıştır. Bu durumun nedeninin derenin üst kısımlarında akıntının hızlı ve Aralık ayında yağışların fazla olması sonucu derede meydana gelen seyrelme olduğu düşünülmektedir.

YSKY'nde, AKM için herhangi bir sınıflandırma verilmemiştir. Ancak, katı madde miktarındaki artışın suyun estetik değerini düşürdüğü ve kullanım alanlarını azalttığı bilinen bir gerçektir. Akarsulardaki katı maddeler, sudaki silt ve kil varlığından kaynaklanabileceği gibi (Alam vd. 2007) atık su deşarjlarından da kaynaklanabilir. Kozlu Deresi’nde Haziran ayındaki AKM ölçüm sonuçları incelendiğinde, en yüksek değer 112 mg/L ile Kozlu sanayi sitesi yakınında bulunan 3 . örneklem noktasında olduğu görülmüştür. İkinci en yüksek değer ise $88 \mathrm{mg} / \mathrm{L}$ ile derenin Karadeniz ile buluştuğu noktada görülmektedir. Yüksek AKM değeri nedeniyle su oldukça kirli ve bulanık olarak görülmektedir. Aralık ayındaki ölçümlerde ise yağışlar nedeniyle AKM değerleri $1 \mathrm{mg} / \mathrm{L}$ 'nin altına düşmüştür. Kuruçay’da yapılan su kalitesi çalışmasında yaz ve kış mevsimi AKM ölçüm ortalamaları sırasıyla $3.2 \mathrm{mg} / \mathrm{L}$ ve $1.3 \mathrm{mg} / \mathrm{L}$ olarak verilmiştir (Mutlu ve Uncumusaoğlu 2016). Çoruh Nehri'ndeki AKM değerlerinin ise 2 farklı istasyonda $16 \mathrm{mg} / \mathrm{L}$ ve $17 \mathrm{mg} / \mathrm{L}$ olduğu rapor edilmiştir (Birici vd. 2017). Kozlu Deresi’nin özellikle yağışların az olduğu yaz döneminde askıda katı madde bakımından oldukça kirli olduğu ve bununda atık su deşarjlarından kaynaklandığı söylenebilir.

Elektriksel iletkenlik değeri suda bulunan çözünmüş iyonların miktarını gösterir. İletkenlik sıcaklığa ve tuz gibi çözünmüş maddelerin varlığına bağlı olarak değişebilir. Ancak, iletkenliğin $1000 \mu \mathrm{S} / \mathrm{cm}$ gibi değeri aşması suyun kirlendiği anlamına gelmektedir (Maraşlıoğlu vd. 2017). Bu çalışmada, iletkenlik değerleri de diğer parametrelerde olduğu gibi yazın daha yüksek kışın ise daha düşük olarak ölçülmüştür. Haziran ayında, en yüksek iletkenliğin ölçüldüğü noktalar 6. ve 3. örneklem noktalarıdır. Buralarda ölçülen değerler sırasıyla $2823 \mu \mathrm{S} / \mathrm{cm}$ ve $1206 \mu \mathrm{S} / \mathrm{cm}$ 'dir. Aralık ayında ölçülen en yüksek değerler ise $626 \mu \mathrm{S} / \mathrm{cm}$ ile 5 . örneklem noktasında ve $502 \mu \mathrm{S} / \mathrm{cm}$ değeri ile 6 . örneklem noktasındadır. Ülkemizde yapılan çalışmalarda rapor edilen en düşük iletkenlik Kuruçay’dadır. Sivas Kuruçay’da kurak dönem ortalama iletkenlik $215 \mu \mathrm{S} / \mathrm{cm}$ ve yağışılı dönem ortalama iletkenlik ise $166 \mu \mathrm{S} / \mathrm{cm}$ olarak belirtilmiştir (Mutlu ve Uncumusaoğlu 2016). Kuruçay’daki iletkenlik değerinin bu kadar düşük olmasının sebebi denizden uzak olması olabilir. Aksu Nehri'nde kurak dönem iletkenlik ortalaması $739 \mu \mathrm{S} / \mathrm{cm}$ ve yağışlı dönem iletkenlik ortalaması $690 \mu$ S/cm (Şener vd. 2017), Biga Çayı'nda ortalama $870 \mu \mathrm{S} / \mathrm{cm}$ (Hacioglu ve Dulger 2009), Mert Çayı'nda da ortalama $1087 \mu \mathrm{S} / \mathrm{cm}$ değerleri rapor edilmiştir (Maraşlığlu vd. 2017). Literatürdeki çalışmalar ile kıyaslandığında Kozlu Deresi'nde kurak dönemde ölçülen $1206 \mu \mathrm{S} / \mathrm{cm}$ ve $2823 \mu \mathrm{S} / \mathrm{cm}$ gibi değerlerin oldukça yüksek olduğu söylenebilir. Bu çalışmadaki 6 . numune noktası, Karadeniz'e oldukça yakın olduğu için buradaki iletkenlik değerinin diğer noktalara kıyasla daha yüksek olması zaten beklenen bir olaydır. Fakat daha önceki numune alma noktalarındaki ölçülen yüksek iletkenlik değerleri, Kozlu Deresi’nin deşarjlar ile kirletildiğini ve suyun saflığının azalmış olduğunu göstermektedir.

Yapılan laboratuvar analizlerinin ardından KOİ, AKM ve İletkenlik değerleri bir Coğrafi Bilgi Sistemleri (CBS) yazılımı olan MapInfo'ya (sürüm 17) aktarılmıştır. Hem yaz hem de kış ölçümleri için Kozlu Deresi'nde KOİ, AKM ve İletkenlik haritaları oluşturulmuştur. Haziran ve Aralık aylarında bulunan KOİ değerleri ile çizilen tematik haritalar Şekil 2 ve 3 'te gösterilmiştir. Benzer şekilde, Haziran ve Aralık aylarında bulunan AKM değerleri ile çizilen tematik haritalar ise Şekil 4 ve 5'de ve İletkenlik için çizilen haritalar da Şekil 6 ve 7'de yer almaktadır. 


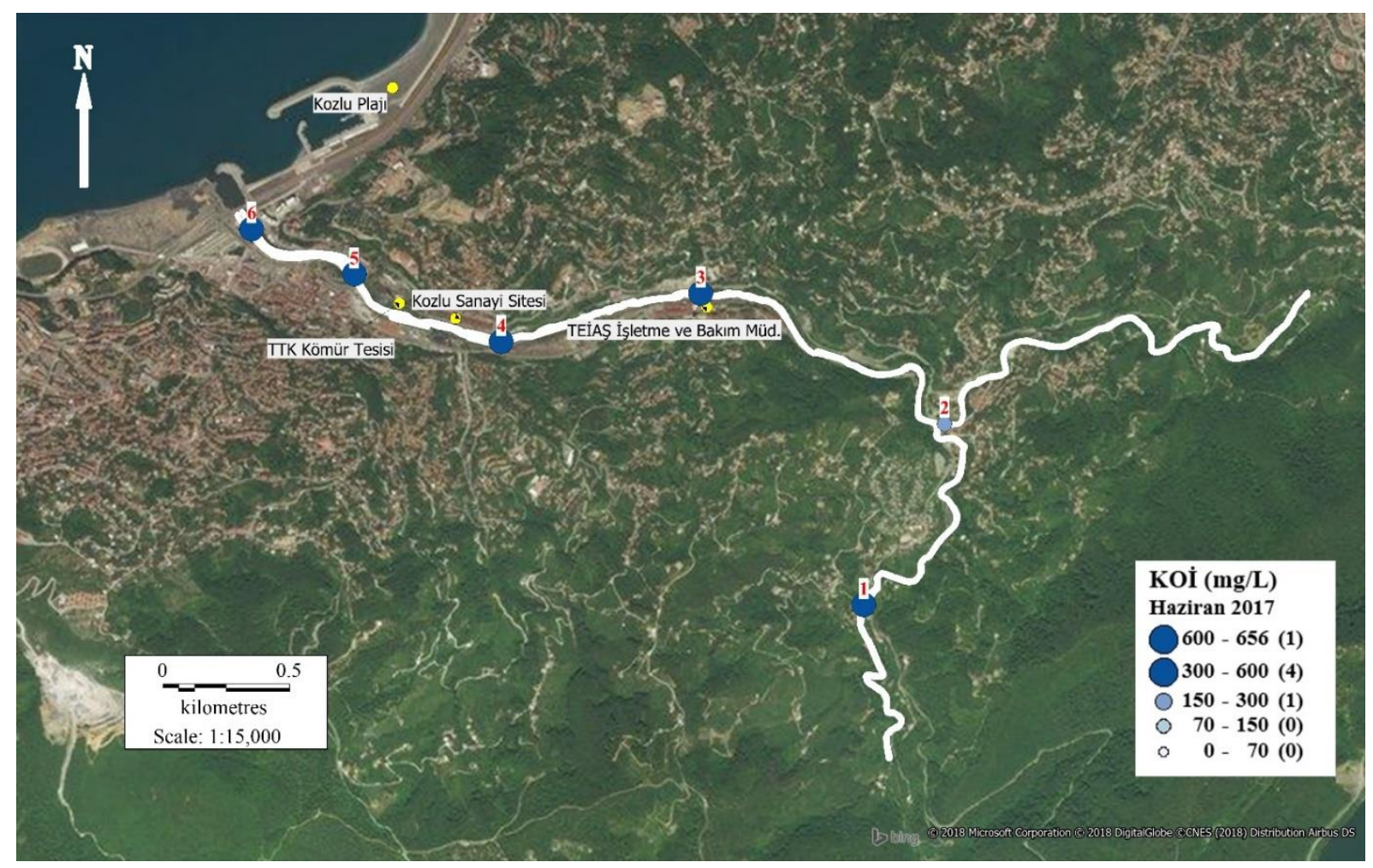

Şekil 2: KOI ölçümleri Haziran 2017

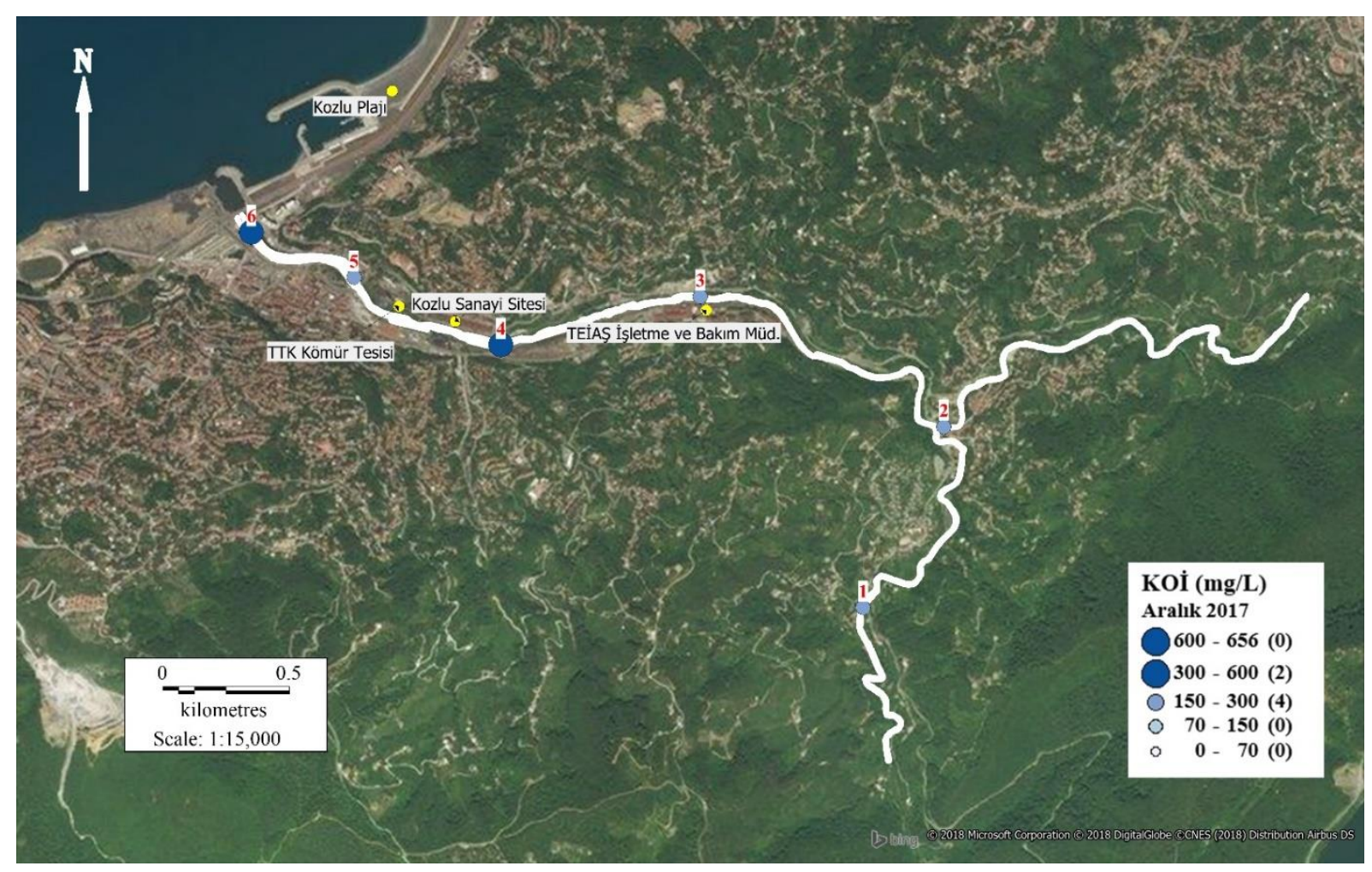

Şekil 3: KOI ölçümleri Aralık 2017 


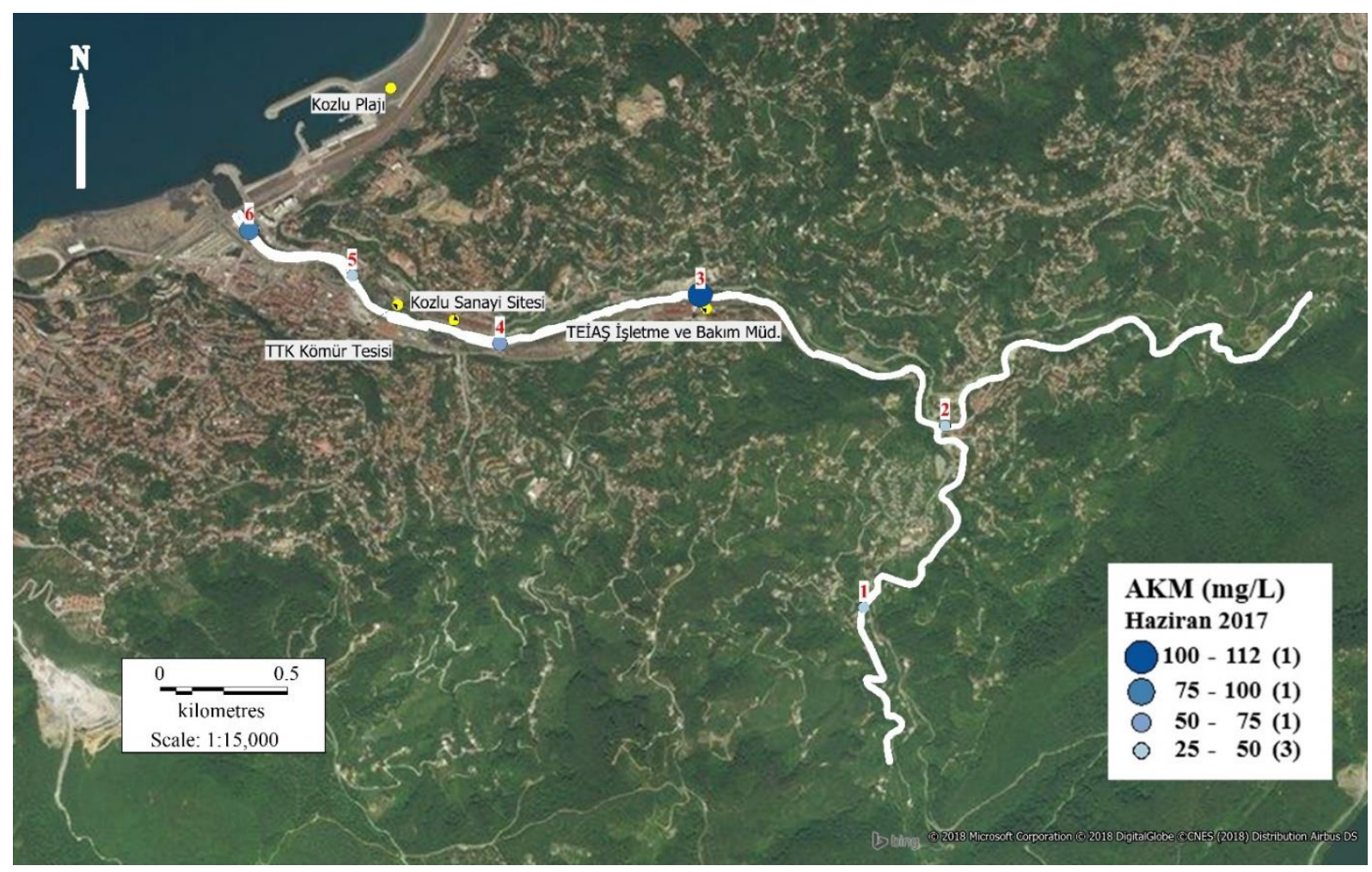

Şekil 4: AKM ölçümleri Haziran 2017

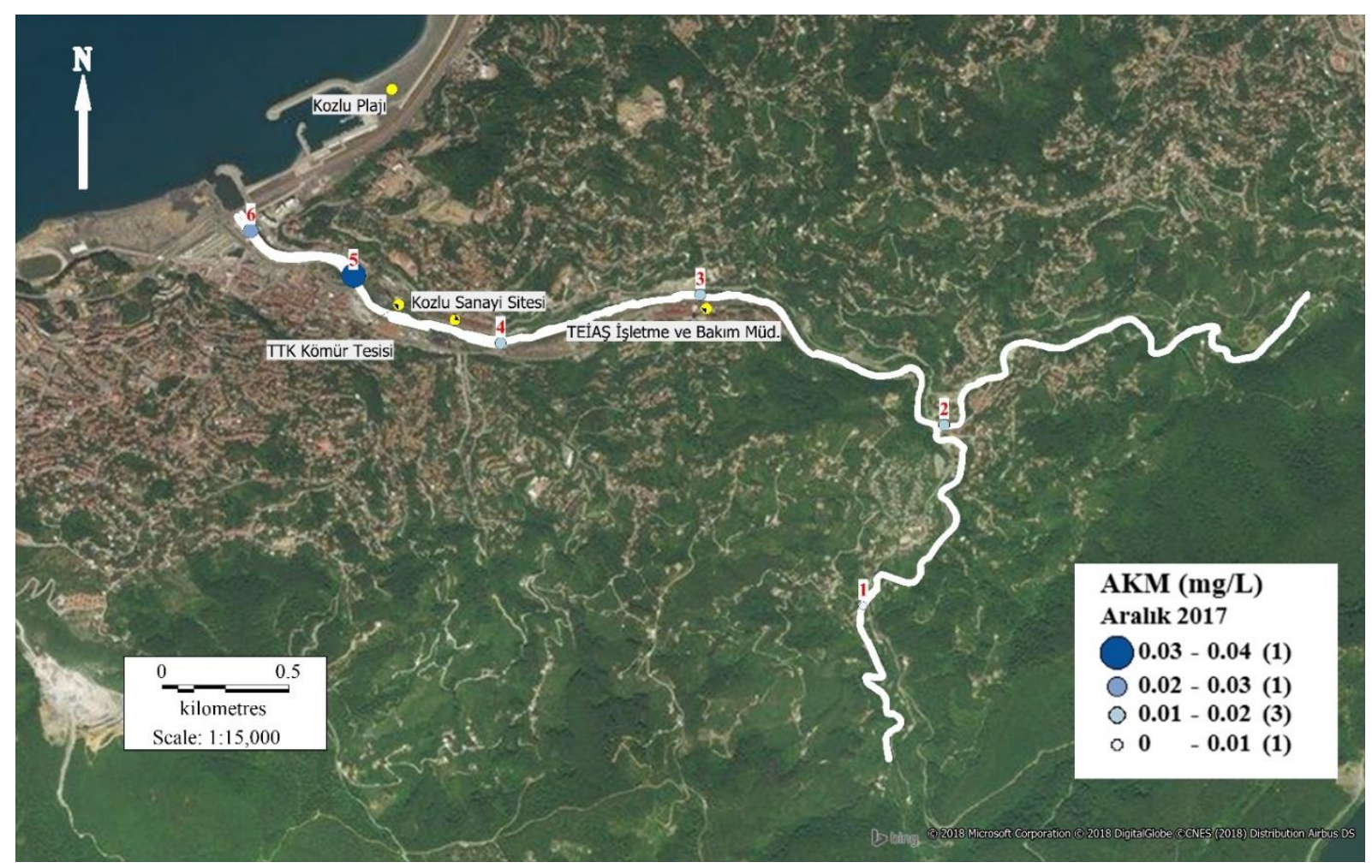

Şekil 5: AKM ölçümleri Aralık 2017 


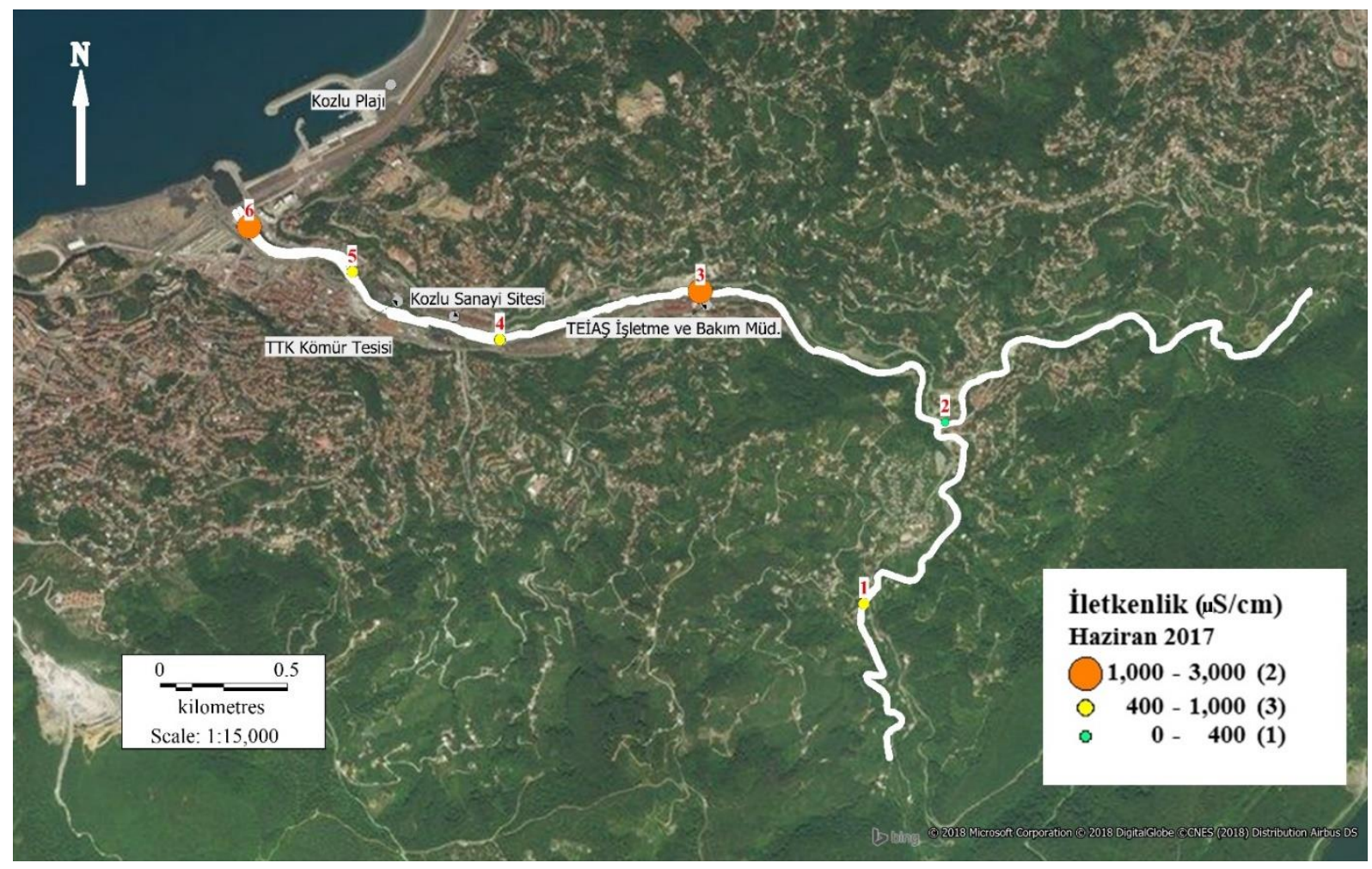

Şekil 6: Iletkenlik ölçümleri Haziran 2017

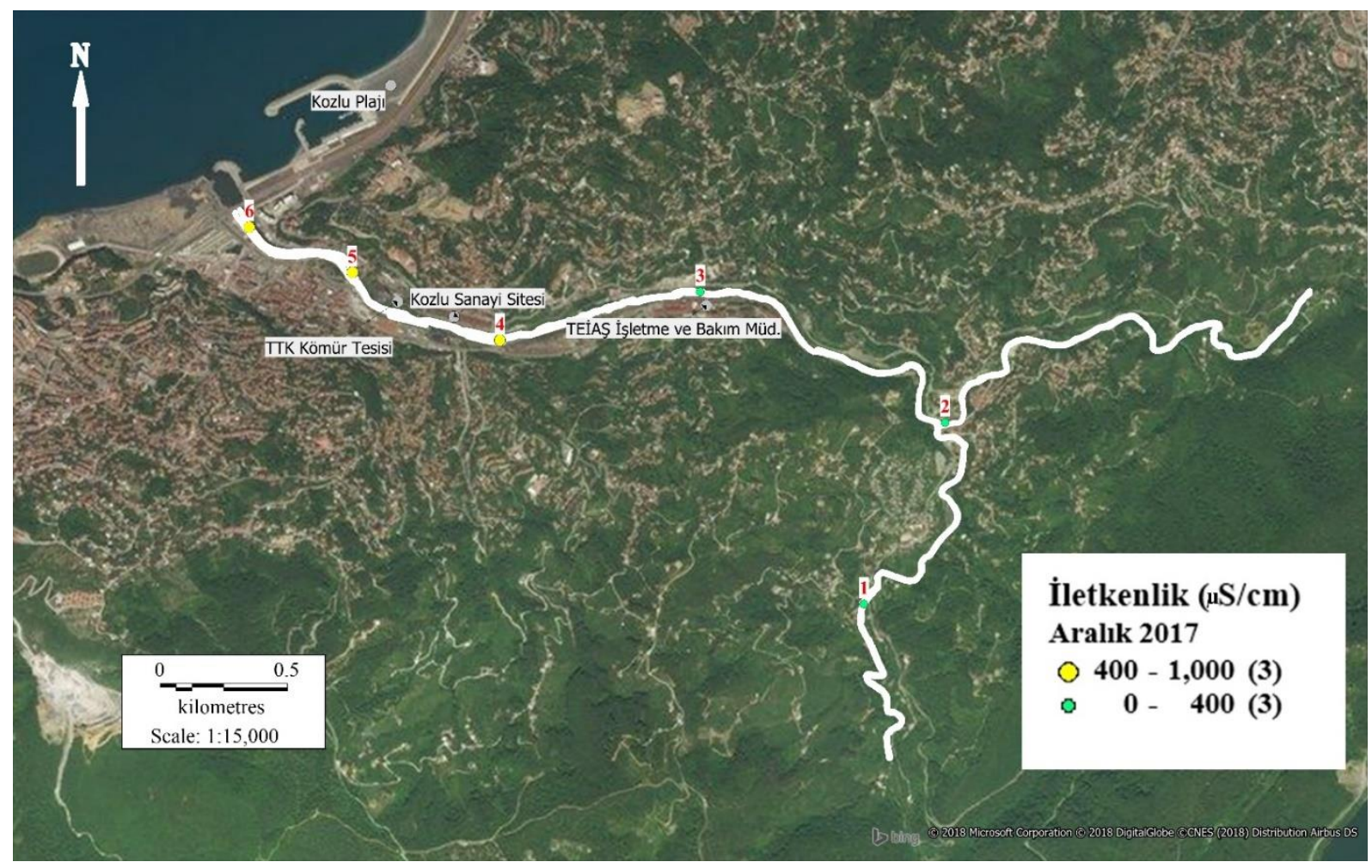

Şekil 7: Iletkenlik ölçümleri Aralık 2017

Haziran ayına ait ölçüm sonuçları ile oluşturulan grafikler (Şekil 2, 4 ve 6) incelendiğinde özellikle 3. ve 6. örneklem noktalarında su kalitesinin oldukça bozulmuş olduğu söylenebilir. 3. örneklem noktası yakınlarında Kozlu Sanayi Sitesinin ve TEİAŞ Çatalağzı İletim Şebekeleri İşletme ve Bakım Müdürlüğü’nün bulunduğu görülmektedir. Su kalitesinin bozulmasının sebebi olarak bu noktalardan dereye deşarj yapıldığı düşünülmektedir. 6. numaralı örneklem noktası ise Kozlu deresinin Karadeniz ile birleşmiş olduğu noktadadır. 
Kozlu Belediyesi'nde atık su arıtma tesisi bulunmadığı için belediyenin atık suları bu noktaya dökülmektedir. Dolayısıyla zaten kirli olan dere daha da kirlenerek Karadeniz'e ulaşmaktadır. Şekil 2 ve 3'teki KOİ için hazırlanan haritalar incelendiğinde, 4 numaralı örneklem noktasında da yüksek KOİ değerleri göze çarpmaktadır. Bu nokta yakınlarında TTK Kozlu Ocak İşletmesi yer almakta ve atıklarını dereye deşarj etmektedir. Şekil 4 ve 5 'teki AKM için hazırlanan haritalar incelendiğinde, AKM kirliliğinin kurak mevsimde su kalitesini ciddi şekilde etkilediği, yağışlı dönemde ise seyrelmeye bağlı olarak önemli bir kirlilik oluşturmadığı görülmektedir. Şekil 6 ve 7'deki iletkenlik haritalarına bakıldığından da yağışların az olduğu haziran ayında 3 ve 6 numaralı örneklem noktalarında yüksek iletkenlik değerleri gözlenmekle birlikte yağışların meydana getirdiği seyrelme etkisiyle Aralık ayında iletkenlik değerlerinin düştüğü görülmektedir.

\section{Sonuçlar ve Öneriler}

Bu çalışmada, Kozlu Deresi’ndeki su kalitesi ilk kez dere boyunca çalışılmış, altı farklı noktadan kurak ve yağışlı dönemlerde alınan su numunelerinin fizikokimyasal parametreleri analiz edilmiş ve YSKY'ne göre su kalite standartlarıyla karşılaştırılarak su kalitesi sınıfları belirlenmiştir. CBS ortamında hazırlanan haritalar ile de kirletici kaynakların tespiti yapılmaya çalışılmıştır. Bölgede herhangi bir tarımsal faaliyet alanı bulunmadığı için yayılı kaynağın olmadığı, noktasal kaynakların ise dereye deşarj yapan Kozlu sanayi sitesi, TTK Kozlu işletmesi ve TEİAŞ bakım işletme şefliği olduğu görülmektedir. Ayrıca, belediyenin evsel atık suları derenin Karadeniz’le buluştuğu noktanın çok yakının da dereye deşarj edilmektedir. Yukarıda bahsedilen baskı ve etkilerden dolayı Yerüstü Su Kalitesi Yönetmeliği’ne göre deredeki su kalitesi yapılan ölçümler sonucu 4. Sınıf çıkmaktadır. Bu bilgiler ışı̆̆ında, Kozlu deresinden içme suyu temini yapmak, rekreasyonel amaçla su kullanmak ve balıkçılık yapmak mevcut haliyle uygun değildir. Derenin Karadeniz'e döküldüğü bölgenin çok yakınında Kozlu Plajının bulunması ve derenin bu bölgelere kirlilik yükü taşımasından dolayı insan sağlığını tehdit edebilecek durumlar söz konusu olabilmektedir. Ayrıca, Kozlu deresi kıyısında bulunan ve dereye deşarj yapan diğer tesisler de su kalitesini ciddi oranda kötüleştirmektedirler. Sonuçlar incelendiğinde, Kozlu Deresi'nde su kalitesini iyileştirebilmek için evsel ve sanayi kaynaklı atık suların dereye verilmesi önlenmeli, acil olarak atık su arıtma tesisi inşa edilmesi önerilmektedir.

\section{Teşekkür}

Bu çalışma, TÜBİTAK 2209-A Üniversite Öğrencileri Araştırma Projeleri Destekleme Programı kapsamında desteklenmiştir. Yazarlar, MapInfo Pro v17 yazılımının lisansı için Başarsoft Bilgi Teknolojileri A.Ş.'ye teşekkür ederler.

\section{Kaynaklar}

Alam M.J.B., Islam M.R., Muyen Z., Mamun M., Islam S., (2007), Water quality parameters along rivers, Int. J. Environ. Sci. Technol., 4, 159-167.

Altaş L., Büyükgüngör H., (2007), Heavy metal pollution in the Black Sea shore and offshore of Turkey, Environ Geol, 52, 469-476.

Altin A., Özölçer İ.Ö., Yildirim Y., (2009), Water pollution in the southern coastal region of the Black Sea, Fresenius Environmental Bulletin, 18(11a), 2170-2180.

APHA, (2005), Standard Methods of Water and Wastewater, 21st Ed., American Public Health Association, Washington, DC., ISBN:0875530478, pp: 2-61.

Birici N., Karakaya G., Şeker T., Küçükyılmaz M., Balcı M., Özbey N., Güneş M., (2017), Çoruh Nehri su kalitesinin su kirliliği kontrolü yönetmeliğine göre değerlendirilmesi, Int. J. Pure Appl. Sci., 3(1), 54-64.

Boyacioglu H., (2006), Surface water quality assessment using factor analysis, Water SA, 32(3), 389-393.

Chang H., (2008), Spatial analysis of water quality trends in the Han River basin, South Korea, Water Research, 42, 3285-3304.

Ekinci D., (2003), İhsaniye Deresi Havzası (Zonguldak) taşkın analizi, Coğrafya Dergisi, 11, 97-118.

Hacioglu N., Dulger B., (2009), Monthly variation of some physico-chemical and microbiological parameters in Biga Stream (Biga, Canakkale, Turkey), African Journal of Biotechnology, 8(9), 1929-1937.

Koç C., (2010), A study on the pollution and water quality modeling of the River Buyuk Menderes, Turkey, Clean - Soil, Air, Water, 38(12), 1169-1176.

Liu Z., Li Y., Li Z., (2009), Surface water quality and land use in Wisconsin, USA - A GIS Approach, Journal of Integrative Environmental Sciences, 6(1), 69-89.

Maraşlığlu F., Gönülol A., Bektaş S., (2017), Assessment of water quality in Mert Stream (Samsun, Turkey) base on some physicochemical parameters, Ecology Symposium 2017 Proceedings Book of Full Papers'1n içinde, Kayseri, Turkey, ss. 77-89.

MGM, (2018), Illere Ait Mevsim Normalleri (1981-2010), Meteoroloji Genel Müdürlügü, https://mgm.gov.tr/veridegerlendirme/il-veilceler-istatistik.aspx?m=ZONGULDAK, [Erişim 2 Ağustos 2018].

Mutlu E., Uncumusaoğlu A. A., (2016), Physicochemical analysis of water quality of brook Kuruçay, Turkish Journal of Agriculture Food Science and Technology, 4(11), 991-998.

Özkan K., Özhan K., Yücel M., (2017), Catchment-Sea interactions in the Black Sea, Black Sea Marine Environment: The Turkish Shelf' in İçinde (Sezgin M., Bat L., Ürkmez D., Arıcı E., Öztürk B., Ed.), Turkish Marine Research Foundation (TUDAV), İstanbul, ss. 98-113.

Søndegaard M., Jensen J.P., Jeppesen E., (2001), Retention and internal loading of phosphorus in shallow, eutrophic lakes, Scient. World J., 1, 427. 
Şener Ş., Şener E., Davraz A., (2017), Evaluation of water quality using water quality index (WQI) method and GIS in Aksu River (SWTurkey), Science of the Total Environment, 584-585, 131-144.

Toroğlu E., Toroğlu S., Alaeddinoğlu F., (2006), Aksu Çayında (Kahramanmaraş) akarsu kirliliği, Coğrafi Bilimler Dergisi, 4 (1), 93 103.

Tsuzuki Y., (2015), Relationships between pollutant discharge and water quality in the rivers from "better" to "worse" water quality, Ecological Indicators, 52, 256-269.

Tuncer G., Karakas T., Balkas T.I., Gökçay C.F., Aygun S., Yurteri C., Tuncel G., (1998), Land-based sources of pollution along the Black Sea coast of Turkey: concentrations and annual loads to the Black Sea, Marine Pollution Bulletin, 36(6), 409-423.

Udimal T.B., Jincai Z., Ayamba E.C., Owusu S.M., (2017), China's water situation; the supply of water and the pattern of its usage, International Journal of Sustainable Built Environment, 6, 491-500.

URL-1, (2016), Zonguldak Il Çevre Durum Raporu, T.C. Zonguldak Valiliği Çevre ve Şehircilik Müdürlüğü, Zonguldak, https://webdosya.csb.gov.tr/db/ced/editordosya/Zonguldak_icdr2016.pdf, [Erişim 2 Ağustos 2018].

URL-2, (2012), Yerüstü Su Kalitesi Yönetmeliği, http://www.mevzuat.gov.tr/Metin.Aspx?MevzuatKod=7.5.16806\&MevzuatIliski=0 \&sourceXmlSearch=, [Erişim 2 Ağustos 2018].

Yan C.A., Zhang W., Zhang Z., Liu Y., Deng C., Nie N., (2015), Assessment of Water Quality and Identification of Polluted Risky Regions Based on Field Observations \& GIS in the Honghe River Watershed, China, PLoS ONE, 10(3): e0119130.

Yayıntas O.T., Y1lmaz S., Turkoglu M., Dilgin Y., (2007), Determination of heavy metal pollution with environmental physicochemical parameters in waste water of Kocabas Stream (Biga, Canakkale, Turkey) by ICP-AES, Environ Monit Assess, 127, 389-397. 